\title{
Language Attitudes Studies Between the Past and the Present: The Current State of Research in the Arab World and Within the Saudi Context
}

\author{
Abdullah Abdulrahman Bin Towairesh ${ }^{1}$ \\ ${ }^{1}$ Department of English Language and Translation, College of Languages and Translation, King Saud University, \\ Riyadh, Saudi Arabia \\ Correspondence: Abdullah Abdulrahman Bin Towairesh, Department of English Language and Translation, \\ College of Languages and Translation, King Saud University, Riyadh, Saudi Arabia. E-mail: \\ abintowairesh@ksu.edu.sa
}

Received: July 6, $2021 \quad$ Accepted: August 10, $2021 \quad$ Online Published: August 18, 2021

doi:10.5539/ijel.v11n5p19 URL: https://doi.org/10.5539/ijel.v11n5p19

\begin{abstract}
Language attitudes studies are integral to our understanding of language-society dynamics, specifically in regions where linguistic diversity can create issues connected to social structure and social cohesion. The field of language attitudes studies heavily impacts research in areas such as language planning and policy, education and workplace inequality, and cultural discrimination. Thus, it is important to have a work that presents an overview of the most important notions and concepts in this field, with a specific focus on topics such as defining language attitudes, the components of an attitude, and the different methods of measuring it. This paper aims at providing this overview in addition to assessing the current status of language attitudes studies in the Arab world and outlining the challenges and opportunities for researchers in this field. One of the significant characteristics of language attitudes research in this region is the lack of studies that focus on the inequality dimension. Many studies in this region have opted to investigate the Standard-Spoken dichotomy and the attitudes of speakers toward foreign languages such as French and English. Researching issues such as the attitudes toward other Arabic varieties and toward migrant guest workers' use of pidgins remains limited in the Arab context. Factors such as cultural rivalry and national pride may represent some of the obstacles in the path of conducting broader studies in the field of language attitudes in this region.
\end{abstract}

Keywords: language attitudes, linguistic inequality, language planning, language and education

\section{Introduction}

Language attitudes research has developed significantly since the early days of the matched guise technique of Lambert et al. (1960) to the more recent work on accent-ism by Roessel et al. (2020). Through all these years, many notions have remained consistent in this field, and certain basic principles have continued their presence as part of its foundation, despite the large number of studies published in this field. In the Arab world, however, the picture is different, and the volume of research in the field of language attitudes is not comparable to other regions with the same characteristics. Thus, we find that only a small number of studies on language attitudes have been conducted and that many of these studies focused on the Standard-Spoken dichotomy. This limited scope can be (to a large extent) a less controversial subject, as opposed to examining the attitudes toward specific spoken varieties, as expressed by the speakers of a different variety. The perception of rivalry and the great sense of pride in local spoken dialects might be among the significant obstacles in the way of conducting language attitudes research in this region. Another topic that has been examined in the Arab world within the field of language attitudes is researching speakers' attitudes toward their own variety of language, which also falls within the category of studies that are not likely to cause any rifts.

This paper presents an overview of language attitudes studies with a focus on outlining the developments that have taken place in this field through the years, the different components of attitude, the methods used for measuring attitudes, and the real-life applications of language attitudes research that can have a strong influence on several domains, such as education, language planning, and linguistic inequality. The next step is to assess the developments in language attitudes research within the Arab world with the aim of discussing the areas that have 
been covered within this region and the difficulties that researchers face when conducting this kind of investigation. Finally, the discussion will turn to the different characteristics of language attitudes studies in the local Saudi context, with an analysis of the similarities and differences in researching this topic, compared with other regions within the broader Arab academic scene.

It is hoped that this paper will be one step in the direction of achieving an understanding of the state of research in this important field by offering a detailed account of the studies that have focused on language attitudes through the years, around the world, and within Arabic-speaking countries in particular. The goal is to produce a short reference on language attitudes research that can be used by students and researchers and that can provide concise information that covers many aspects of this field with a special focus on the Arab world and the Saudi context.

\section{Defining Language Attitudes}

Baker (1992) compiled different definitions of attitude used by different researchers, which illustrates the varying understanding of this concept. For example, attitude is defined as a willingness to react favorably or unfavorably to an object, person, institution or event. The problem with this definition, however, is that it is not concise in describing the stimuli for attitudes. Someone could have attitudes toward things that are not mentioned in the definition, like languages and communities. A more comprehensive definition states that attitudes position objects of thought on a scale of judgment. Fasold (1984) wrote about two contradictory points of view on attitudes, which are the mentalist and behaviorist interpretations. According to the mentalist view, an attitude is an internal state of readiness which, if provoked, drives our response to the stimuli. The problem here lies in the difficulty of measuring an attitude if it is an internal state. On the other hand, behaviorists believe that attitudes can be deduced from the way people react in social situations, which makes the act of observing the most important tool for the researcher. However, the drawback here is that researchers cannot use attitudes to predict future behavior.

If we choose a middle ground between these two views, we can say that an attitude is an internal state that produces a reaction that will indicate the internal disposition if analyzed. This way we can say that attitudes can be used in predicting and explaining behavior. In language attitudes studies, researchers have managed to predict certain kinds of behavior, like the use of the variant (r): $[\mathrm{r}]$ instead of the variant (r): $[\varnothing]$ when the speaker is trying to be associated with a higher social class (Labov, 1972). Researchers have also acquired some understanding of specific social phenomena, like the reaction of landlords when contacted on the phone by potential tenants from different ethnicities with different accents (Purnell et al., 1999).

\section{Attitude Components}

Ajzen (1988) discussed the existence of three attitude components: cognition, affect, and action. The cognitive component of an attitude describes the convictions and beliefs of individuals and members of societies toward a certain variety of speech and language (the word "variety" here will be used as a general term that includes languages and dialects). The affective component is usually manifested in the way people express their feelings toward this variety, and the action component is what reveals their commitment to it. A strong positive feeling toward a certain language, for example, will result in an effort to learn that language or enroll one's children in a school that teaches it. However, the cognitive and affective components do not always have to be in accord with each other. In some cases, the pressures of political correctness might lead someone to express positive feelings toward a certain variety even though he/she may think that it should not even exist.

Ladegaard (2000) adopted a very similar model of language attitude components with minor differences in terminology. He used the terms "knowledge," "emotion," and "behavior" when discussing the issue, which gives a more generalized view that helps in capturing the potential concepts that might be included under these headings.

\section{Measuring Language Attitudes}

Measuring language attitudes can be accomplished by different methods, each having its own advantages and disadvantages. One of the most common methods for measuring language attitudes is the matched guise technique, which usually aims at comparing the attitudes toward the use of two varieties. The procedure consists of recruiting a speaker who is fluent in these two varieties and asking that person to record a certain passage once in each variety. The recordings will then be played separately to a number of listeners after introducing other speakers, between the two recordings. The listeners will then be asked to rate the speaker's personal qualities like friendliness and intelligence. Because both passages are delivered by the same speaker, any discrepancy in rating the speaker's qualities will definitely be a reflection of the listeners' attitude toward the 
variety and not the speaker (Obiols, 2002).

However, one of the drawbacks associated with this method is artificiality. Asking people to judge other people's personal qualities by only listening to them cannot be perceived as natural. Another drawback is the possible loss of accuracy in the results due to the feeling of boredom by the listeners. After listening to the same thing for two or more times, listeners might lose concentration and might want to finish the experiment very quickly. A possible solution for these two problems is the use of a modified form of the matched guise method, which includes urging the listeners to perform certain tasks by speakers who use different varieties instead of asking them to rate the speakers' personal qualities. Only one variety will be used with every group of listeners, and attitude will be measured by calculating the number of respondents to each task. It is very important, however, to make sure that all groups of listeners come from the same background to achieve uniformity. An example of the use of this method is an experiment by Bourhis and Giles (1976) in which they aimed at eliciting attitudes toward Welsh, RP English (Received Pronunciation), and English with a Welsh accent. Cinema patrons from the same speech community were asked to fill out questionnaires by an announcer who used a different variety each night. The number of people who responded to the request every night was matched with the variety used, which showed that the highest level of cooperation was recorded with the use of Welsh. Responding to the use of English with a Welsh accent came second, and RP English came last.

Another method of examining language attitudes is the semantic differential scale, which consists of a bipolar scale with two contradictory adjectives at both sides and a number of blank spaces between them. The listeners are asked to put a mark on one of these spaces depending on their feelings toward the variety or the speaker to whom they are listening. For example, if the two adjectives are honest and dishonest and the listener feels that the speaker is dishonest, he/she would mark the space closest to the corresponding adjective. If the listener has neutral feelings about the speaker, he/she would then mark the middle space (Heise, 1970).

Calculating the results from the scale is done by multiplying the number of marks on each space by the value of that space itself. The results for all the spaces are then added, and the total is divided by the number of participants. The final result represents the level of attitude associated with the adjectives in question.

Other methods of measurement for language attitudes include observation, questionnaires, and interviews. However, Baker (1992) questioned the validity of attitude measurements in general because of the concerns about the lack of accuracy. Due to certain social circumstances, some people might feel obliged to respond to attitude tests in a certain way that would make them look more prestigious, or help them avoid being criticized by the rest of the community. Also, the objectives of the researcher conducting the test might affect people's responses, in that such objectives may limit the participants' choices in the provided measurement tool, which can result in producing attitudes that did not exist for the participant before the test.

\section{Applications for Language Attitudes Studies}

\subsection{Education}

Throughout the history of language attitudes studies, researchers have had several reasons for conducting their experiments. One of the main reasons behind carrying out a language attitudes study is to look at the relationship between the outcomes of education and the attitudes of teachers and students. The way teachers feel about the language varieties used by their students has always played an important role in the success, fairness, and development of the educational process.

Williams et al. (1972) devised a two-dimension scale with the aim of capturing teachers' stereotypical views of their students' level of success. The first dimension in this scale is confidence-eagerness, and the second is ethnicity-nonstandardness. The researchers claimed that the validity of this scale comes from the fact that it represents the main causes for teachers' reaction to their students' linguistic varieties. The test involved asking a group of teachers from different races to rate students from White, Mexican American, and African American backgrounds according to the confidence-eagerness and ethnicity-nonstandardness model. After this task, the researchers asked the teachers to watch interviews that were conducted with these students and then rate them again using the same model. The test revealed that stereotypes played an important role in teachers' decisions, resulting in White students being rated as more confident, eager, nonethnic, and standard than students from other ethnic backgrounds in both procedures by all teachers. Black and Mexican American students were rated low on both scales in the first procedure by most teachers, and in the second procedure, teachers rated students from their own ethnicity as being more nonethnic and standard than did teachers from other ethnicities. To prevent stereotypical views from affecting teachers' expectations, the researchers suggested that teachers should be trained to be sensitive to the variations in their students' social dialects and performance. 
Additionally, the influence of language attitudes on achievement in second language learning is another aspect of the educational applications for language attitudes studies. Spolsky (1989), for example, listed language attitude as an important condition for successful second language learning. Positive attitudes toward a certain language drive learners to be integratively motivated to learn that language, which in many ways acts as a more affective incentive in this regard. Students who are integratively motivated are more active in the classroom, more likely to volunteer answers, and less likely to drop out of language classes. In their effort to determine the relationship between attitudes and second language learning, Gardener et al. (1997) conducted a study on a group of university students learning French as a second language. In this study, they used a modified version of Gardener's Attitude and Motivation Test Battery (AMTB), which is a method that has been devised to measure attitudinal and motivational variables like integrativeness, motivation, and language anxiety. The researchers discovered that positive attitudes toward the target language contributed to the motivation to learn that language, which, in turn, increases the level of achievement and confidence for the learners.

Some researchers have downplayed the influence of language attitudes on the process of second language learning. Macnamara (1973), for example, indicated that the connection between attitudes and language learning is not as strong as it is reported to be, and that in many cases the influence of language attitudes is negligible. He argued that in some cases, people managed to learn languages even when they had no attitudes (or sometimes, negative ones) toward them. He listed a number of examples, like the adoption of English by members of Irish society, with all their negative attitudes toward English, and the acquisition of German by a Canadian person after suddenly moving to Berlin without originally having had specific attitudes toward German. Macnamara, however, did not account for the sense of obligations in these cases that left the people in question with no choice but to learn the second language. The only possible choice for them in these situations was to learn the second language; otherwise, they would have encountered a great deal of difficulty in adapting to the surrounding environment. However, in normal second language acquisition cases, language attitudes have proved to be an integral part of the learning process.

\subsection{Language Policies and Planning}

Language attitudes have always been important as a factor that drives language policies and planning in many societies. If the members of a society have spiritual or nationalistic ties with a certain language, these ties will constitute the basis for choosing it as the standard in that society. A clear example of that is in the way Arabic is revered as the language of the Holy Scripture for Muslims (The Quran), and as the medium chosen by God (according to the Islamic belief) to convey his message to human beings (Glassé, 1989). Additionally, Arabic is also considered to be a unifying factor among all the Arab countries and a symbol of sovereignty, especially in countries that had a history of colonialism.

In Algeria, for example, the French colonial authorities rejected Arabic in official governmental uses beginning in 1938, which was extremely frustrating for the Algerians. However, after the country gained independence, Algerians implemented an entirely opposite language policy, designating only Standard Arabic as the official language in government and in education, and giving it a highly revered status in the country. This decision, however, did not take into account the fact that Standard Arabic was not the most commonly used variety in the country, and it also did not recognize the existence of Berber as a minority language in Algeria (Ager, 2001). The radical reaction toward the unfair colonial language policies resulted in another unfair situation that disadvantaged Berber speakers by preventing them from using their native language in official contexts. This, however, changed in 2016 when Algeria recognized Berber as an official language (it was recognized as a national language in 2002).

The original language policies of Algeria also created an impractical linguistic situation because it did not acknowledge the use of French, even though it was commonly used among the population. Additionally, despite the fact that Algeria is the second largest French-speaking country, the government did not place participating in the international Francophone movement at the top of its priorities (Ager, 2001).

\subsection{Language Inequality}

Another application for language attitudes studies is in the field of studying social structures and social inequality. Certain acts of discrimination and cases of social inequality in a society can be traced back to the issue of language attitudes. A negative attitude toward a specific variety might result in unfair treatment of the speakers of that variety, in areas that can include education, employment opportunities, and housing. An example of language attitudes-driven discrimination was discussed by Purnell et al. (1999) in what they called the housing discrimination. In this study, one of the researchers, John Baugh, employed his ability to use three different dialects in examining landlords' attitudes toward the speakers of these varieties. Using African American 
Vernacular English (AAVE), Chicano English (ChE), and Standard American English (SAE), Baugh contacted landlords with the aim of making property inspection appointments. He called every landlord three times, using a different dialect and giving different contact numbers every time. The result of this experiment showed that landlords did discriminate against Baugh when he used AAVE and ChE, especially in areas where the White population is in the majority.

Language attitudes studies can also be used to detect discriminatory behavior in the workplace. A person's language or variety can play an important role in his or her career, as some superiors may, sometimes unconsciously, associate negative traits with certain language varieties, which makes them turn down applicants who use these varieties. Terrell and Terrell (1983) studied the attitudes of workers in employment agencies toward AAVE by sending a group of African American women with similar, but fictitious, qualifications to these agencies to apply for secretarial jobs. Half of these women spoke Standard English and the other half spoke AAVE. The researchers discovered that SE speakers were given more time during interviews, more job offers, and higher wages than the AAVE speakers. Given the fact that all applicants were from the same race and sex and that all of them had similar qualifications, the only possible reason for the clear difference in responses from the employment agencies was the applicants' speech varieties.

Moreover, language-based discrimination in the workplace does not stop at employment agencies but extends to hiring managers. Henderson (2001) examined the attitudes of a group of hiring managers toward AAVE, with the aim of determining the influence of the job applicant's dialect on the decisions made by the managers. In one stage of Henderson's experiment, she tape-recorded 14 speakers while they talked about problems they encountered in their previous jobs. She divided the speakers into four different groups comprising four guises: (a) standard grammar and phonology, (b) standard grammar and AAVE phonology, (c) AAVE grammar, and (d) standard grammar and AAVE lexicon.

The recordings were then played to the hiring managers, who were asked to rate the speakers' personal traits, solidarity traits, and job suitability. Choosing this method is justified by the fact that many job interviews were being conducted on the phone at the time. The results indicated that speakers who had AAVE aspects in their speech were rated very low on the job suitability scale, including one AAVE speaker who was rated 1, which was the lowest score, even though she had an MBA. When the managers were asked to choose a definition for AAVE, 15 of them thought that it was not a dialect and that it was only poor English. Thirteen of the managers thought that it was a dialect that reflected the social history of African Americans, while 10 thought it was used by African American to express their cultural identity, and four thought it was a dialect related to West African languages. The way in which stereotypical views can influence the choice of hiring managers can be quite damaging to the recruitment process. Slight differences between the applicant's language variety and the standard form of a language may drastically reduce the applicant's chances of getting the job.

\subsection{Language Role in Society}

Language attitudes studies can also help in determining the designated roles for the different varieties in a speech community. In some cases, one variety is used in informal situations as a symbol of group identity, and another is used in the workplace and as a medium for education. Some informal varieties, however, are accepted as a symbol of group identity more than others. In a language attitudes study, high-school students in Quebec did not feel comfortable listening to an interview where the guest used informal Canadian French with a presenter who used European French. On the other hand, Welsh students were satisfied to hear an interviewee speaking with a broad Welsh accent to a presenter who was using RP English. In comparing these two cases we can see that English with a Welsh accent is identified as a group marker in Wales more clearly than French Canadian would be in Quebec (Bourhis \& Giles, 1976).

\section{Language Attitudes Studies in the Arab World}

In the Arab world, language attitudes studies can be described as limited in both the number of publications and the type of factors included in the analysis. The focus on studying attitudes toward the speakers' own language variety or toward Standard Arabic is significant and can contribute to the broader body of literature in this field. However, this focus will not be very influential in addressing several of the pressing issues connected to language attitudes, such as educational, linguistic, or workplace inequality. There are no native speakers of Standard Arabic using it in their daily lives because of the diglossic situation in the Arab world. This clearly excludes studies that focus on this variety from the scope of inequality research. Additionally, studies that focus on a speaker's attitudes toward his or her own variety do not usually assess attitudes toward other varieties, which does not contribute to the efforts to understand prejudices and examine the participants' linguistic bias.

Nonetheless, there are studies that have addressed speakers' attitudes toward other varieties in this region, albeit 
under specific circumstances, such as having an author from outside the Arab world or in unpublished academic theses. These limitations show the level of complexity involved in conducting research in this field within this region. Therefore, it is important to examine the reasons behind the lack of a substantial body of literature on language attitudes in the Arab world, and whether factors such as national pride and cultural rivalry have any impact on this issue.

One of the early studies on language attitudes in the Arab world was conducted by Herbolich (1979), which focused on the attitudes of Egyptian Arabic speakers toward other Spoken Arabic varieties. In this study, the participants were asked to rate the favorability of "vernaculars" such as Syrian, Saudi, and Libyan Arabic, with the use of a semantic differential scale, after listening to matched guises. In this experiment, the researcher was from outside the local speech community; which might have facilitated the process of data collection because of the sense of impartiality connected to this situation.

In another study within the Arab world, Bouhamama and Bouhamama (2015) examined Kuwaiti university students' attitudes toward the use of Standard Arabic in comparison with English language in the educational context. The results indicated that the participants, in general, had positive attitudes toward Standard Arabic, with many of them favoring it over English as a medium of instruction. The data also showed that the female university students in this study had stronger positive attitudes than did their male counterparts within the same age group. Again, the fact that English is a foreign language in Kuwait and that Standard Arabic is almost no one's first language makes the impact of this kind of study on inequality issues marginal. Both the participants and the researchers did not have to worry about any reservations when discussing the varieties involved in this research because of the understanding that English is a distant foreign language and the fact that Standard Arabic is part of the speakers' identity.

In a similar project, Fakhet (2015) added French to Standard Arabic and English in the process of examining language attitudes among Algerian university students. The study revealed that there were no negative attitudes toward any of the languages included in the analysis, with Arabic being the most valued language in the solidarity dimension, whereas French and English were regarded extremely positively in the status dimension. The same concerns about the impact on language inequality objectives raised in the Kuwaiti study are relevant in the study by Fakhet (2015) as well. However, this does not minimize the important role these studies can play in understanding some of the challenges in the educational system and in exploring the language maintenance and shift dynamics in the target societies.

The focus on examining the attitudes towards a foreign language (either individually or in relation to Arabic) is also a common theme in many of the studies conducted in other Arab countries. For example, in the Qatari context, researchers examined the attitudes of university students toward the utility of Arabic and English in education and communication. In this study, gender emerged as a very strong factor in determining participants' linguistic attitudes (Mustafawi et al., 2021). In the Lebanese context, however, a recent study only focused on English language within the broader topic of Linguistic Imperialism and the growing influence of English in culture and education (Azzi, 2020).

The Standard-Spoken dichotomy in the Arabic-speaking world is another dimension that has been covered in several language attitudes studies, with the aim of understanding speakers' views on the issues that result from this diglossic situation. These two varieties, however, are both considered part of the speaker's linguistic repertoire, and thus examining participants' attitudes toward them continues the tradition of research that does not explore one's prejudices toward the language or the dialect of the other in this region.

In the Jordanian context, for example, Saidat (2010) examined the attitudes of Jordanians from both sexes and different age groups toward the use of Modern Standard Arabic (MSA) and Spoken (nonstandard) Arabic. The results showed that female and younger speakers held more positive attitudes toward Spoken Arabic than did male adults, and that many participants confused the concepts of MSA with Classical Arabic (CA, the language of the Quran). The author presented a number of explanations for the sentiments expressed in his study, which focused on the social composition of the society and the evolving perception of the value of MSA for younger speakers as they mature.

\section{Language Attitudes in the Local Saudi Research Scene}

Saudi researchers have taken the important step of examining the attitudes toward language varieties that are not used by their research participants, which is an effort that can contribute to the greater goal of understanding the issue of linguistic inequality. However, the studies that have been conducted in this area have not gone beyond examining the attitudes toward other local Saudi dialects and have not received a wider dissemination, because they have remained in the classification of academic theses (unpublished studies). Going beyond the boundaries 
of local Saudi dialects requires the involvement of other language varieties used within the society in the examination process, including the Asian guest workers' pidgin and other non-Saudi Arabic dialects (spoken by Arab expatriates). Including these two variables in language attitudes studies would be extremely influential in presenting a clearer understanding of the sociolinguistic situation in this society and would improve our knowledge of the direction of language attitudes.

One of the studies that have examined language attitudes in Saudi society with a focus on the varieties spoken by others is Alrumaih's (2002) MA thesis on Najdi Arabic speakers' perception of the other varieties spoken within Saudi Arabia. In this study, the participants showed positive attitudes toward their own language variety in comparison with other varieties spoken locally, but did rate Najdi Arabic as more pleasant or correct than Modern Standard Arabic or Classical Arabic.

In another academic thesis, Aldosaree (2016) examined the attitudes of participants from different regional backgrounds toward three local Saudi varieties: Hijazi, Najdi, and Janoubi Arabic. The results of this study indicated that age was an important factor in determining the level of awareness of local Saudi dialects, with college students being more accurate than high school students in identifying the different language varieties. The data also revealed that the participants in the younger age group used negative terms to describe Hijazi Arabic, as opposed to those at the college level, which can be an indication of the participants' perceptions and prejudices.

Alahmadi (2016) did actually publish her study about the attitudes toward Urban Meccan Hijazi Arabic, but the fact that it focused only on the speakers of that variety limits its impact on the inequality dimension of the language attitudes field. In this study, the analysis involved specifying the most important factors that can influence language attitudes in a society which, according to the researcher, included age, sex, and the educational level in the Meccan society. The study utilized a 5-point Likert-scale in the data collection process which involved 80 participants from both sexes and different age groups. The results indicated that all participants had positive attitudes toward their own variety, with older speakers showing more interest in expressing support and pride than younger speakers. The study also showed that participants in the uneducated group claimed that they were the best representatives of Urban Meccan Hijazi Arabic because of their working-class professions that allowed them to be in contact with common people using the spoken variety, in situations that did not involve written or formal Arabic.

Language attitudes studies in the Arab world and within the Saudi context are not limited to the studies mentioned above, but an overview of the literature shows that the number of publications on this topic is smaller than expected and that the factors included in the analysis have to be expanded. The issue of linguistic inequality can only be addressed when examined properly, and the examination must focus on the attitudes toward varieties spoken by the more vulnerable segments of the society, including minorities and guest workers in the Arab world.

\section{Conclusion}

Language attitudes studies help us achieve a level of understanding for some of the issues connected to our societies like group identity and social inequality. They can also be instrumental in finding solutions to some of our language-based educational and social issues, by focusing attention on their root causes and origins. Issues of linguistic diversity and cultural tolerance are strongly connected to the field of language attitudes, and any development in this field will have a positive impact on these issues by increasing people's awareness of existing prejudices and discriminatory behavior.

In this paper, the aim was to examine the current state of researching language attitudes in general, starting with a review of the most important characteristics of this field since its beginning. This included discussing the different points of view on defining attitudes to come up with a comprehensive definition that accounts for all the possibilities encompassed in an attitude, including the different reactions and the different stimuli. The analysis also covered attitude components and the advantages and disadvantages of the different methods of measuring language attitudes, including the matched guise and the semantic differential scale techniques. The discussion in this initial section concluded with a review of the areas to which language attitudes studies can be applied, such as education, workplace inequality, and understanding social structure.

The examination continued by discussing studies conducted in the Arab world, outlining the areas that need to be explored more thoroughly in this region. The lack of focus on the linguistic inequality dimension in language attitudes studies within the Arab world is evident and warrants an investigation of its main causes and the difficulties and obstacles that researchers face in this field. The diverse composition of societies in the Arab world, in addition to the complex nature of the social issues facing the members of these societies, necessitate 
maximizing the efforts to examine language attitudes in this region. One of the most prominent features of societies in the Arab world is the presence of immigrants (in countries like Jordan and Lebanon) and migrant guest workers from Asia (in the Gulf countries). Conducting language attitudes research that involves the varieties spoken by these groups will have a remarkable impact on our understanding of the social composition of these societies and on creating a clearly defined picture of the sociolinguistic situation in this part of the world. Issues such as inequality and discrimination in education, in service encounters, airports, and in the workplace are evidently missing from the literature on language attitudes in the Arab world and should be part of any future investigation on this topic, specifically with regard to the varieties used by minorities.

\section{Acknowledgments}

This work was supported by King Saud University through the Deanship of Scientific Research and the Research Centre at the College of Languages and Translation.

\section{References}

Ager, D. E. (2001). Motivation in language planning and language policy. Clevedon, Multilingual Matters.

Ajzen, I. (1988). Attitudes, personality, and behavior. Milton Keynes, Open University Press.

Alahmadi, S. (2016). Insight into the attitudes of speakers of Urban Meccan Hijazi Arabic towards their dialect. Advances in Language and Literacy Studies, 7(2), 249-256.

Aldosaree, O. (2016). Language attitudes towards Saudi dialects. Unpublished MA thesis. California State University, California, USA.

Alrumaih, A. (2002). Najdi perceptions of Saudi regional speech. Unpublished MA thesis. Michigan State University, Michigan, USA.

Azzi R. (2020) Linguistic Imperialism and Attitudes towards Learning English in Lebanon: An Exercise in Critical Pedagogy. In S. Troudi (Ed.), Critical Issues in Teaching English and Language Education. Palgrave Macmillan, Cham. https://doi.org/10.1007/978-3-030-53297-0_5

Baker, C. (1992). Attitudes and language. Clevedon, Multilingual matters.

Bouhamama, D., \& Bouhamama, S. (2015). Attitudes of Kuwaiti university students towards Modern Standard Arabic (MSA). College Student Journal, 49(3), 466-472.

Bourhis, R., \& Giles, H. (1976). The language of cooperation in Wales: A field study. Language Science, 42, $13-16$.

Fakhet, I. (2015). A sociolinguistic study of language attitudes in Algeria. Unpublished MA thesis. Yarmouk University Faculty of Arts, Irbid, Jordan.

Fasold, R. W. (1984). The sociolinguistics of society. Oxford, Blackwell.

Gardener, R. C., Tremblay, P. F., \& Masgoret, A. M. (1997). Towards a full model of second language learning: An empirical investigation. The Modern Language Journal, 81(3), 344-362. https://doi.org/10.1111/j.1540-4781.1997.tb05495.x

Glassé, C. (2001). The concise encyclopedia of Islam. London, Stacey International.

Heise, D. R. (1970). The semantic differential and attitude research. In G. F. Summers (Ed.), Attitude measurement (pp. 235-253). Chicago, Rand McNally.

Henderson, A. (2001). Is your money where your mouth is? Hiring managers'attitudes toward African American Vernacular English. Unpublished doctoral thesis. University of Pennsylvania, Philadelphia, USA.

Herbolich, J. (1979). Attitudes of Egyptians towards various Arabic vernaculars. Lingua, 47, 301-321. https://doi.org/10.1016/0024-3841(79)90077-9

Labov, W. (1972). Sociolinguistic patterns. Philadelphia, University of Pennsylvania Press.

Ladegaard, H. J. (2000). Language attitudes and sociolinguistic behavior: Exploring attitude-behavior relations in language. Journal of Sociolinguistics, 4(2), 214-233.

Lambert, W. E., Hodgson, R. C., Gardner, R. C., \& Fillenbaum, S. (1960). Evaluational reactions to spoken languages. Journal of Abnormal and Social Psychology, 60(1), 44-51. https://doi.org/10.1037/h0044430

Macnamara, J. (1973). Attitudes and learning a second language. In R. W. Shuy \& R. W. Fasold (Eds.), Language attitudes: Current trends and prospects. Washington Georgetown University Press. 
Mustafawi, E., Shaaban, K., Khwaileh, T., \& Ata, K. (2021). Perceptions and attitudes of Qatar University students regarding the utility of Arabic and English in communication and education in Qatar. Language Policy. https://doi.org/10.1007/s10993-021-09590-4

Oboils, P. M. S. (2002). The matched guise technique: A critical approximation to a classic test for formal measurement of language attitudes. Catalunya, Generalitat de Catalunya.

Purnell, T., Idsardi, W., \& Baugh, J. (1999). Perceptual and phonetic experiments on American English dialect identification. Journal of Language and Social Psychology, 18(1), 10-30. https://doi.org/10.1177/0261927X99018001002

Roessel, J., Schoel, C., \& Stahlberg, D. (2020). Modern notions or accent-ism: Findings, conceptualizations, and implications for interventions and research on nonnative accents. Journal of Language and Social Psychology, 39(1), 87-111. https://doi.org/10.1177/0261927X19884619

Saidat, A. M. (2010). Language attitude: The case of Jordan. International Journal of Academic Research, 2(6), $235-243$.

Spolsky, B. (1989). Conditions for second language learning: Introduction to a general theory. Oxford, Oxford University Press.

Terrell, S. L., \& Terrell, F. (1983). Effects of speaking Black English upon employment opportunities. Journal of the American Speech-Language-Hearing Association, June, 27-29.

Williams, F., Whitehead, J., \& Millar, L. (1972). Relations between language attitudes and teacher expectancy. American Educational Research Journal, 9(2), 263-277. https://doi.org/10.3102/00028312009002263

\section{Copyrights}

Copyright for this article is retained by the author, with first publication rights granted to the journal.

This is an open-access article distributed under the terms and conditions of the Creative Commons Attribution license (http://creativecommons.org/licenses/by/4.0/). 